\title{
Relationship Between Alcoholics Anonymous 12 Steps Facilitation and Development of Competencies in Rehabilitation Facilities in Central and Nairobi Regions, Kenya
}

\author{
Waweru Muriithi Catherine K. Mumiukha Owen Ngumi \\ Department of Psychology, Counselling \& Educational Foundations, Egerton University \\ P.o. Box 536 Egerton
}

\begin{abstract}
Helping an alcoholic overcome addiction calls for an appropriately planned and skillfully managed processes that offer personal support and guidance, necessitating effective approaches in the treatment of alcohol rehabilitation. Despite the growth of rehabilitation facilities in the recent past, statistics indicate that approximately $90 \%$ of alcoholics are likely to experience at least one relapse over a four-year period after treatment. This is an indication that recovering alcoholics may have not gained sufficient competencies while in rehabilitation to avoid the relapse. An understanding of how the AA 12 steps facilitation influence the development of competencies among recovering alcoholics is therefore key to their reintegration into society. The study adopted behavioural, Adlerian and person centred theories for its theoretical framework. The study employed the ex-post- facto correlational research design with an accessible population of 202 recovering alcoholics and 81 addiction counsellors in 17 rehabilitation facilities in Central and Nairobi regions employing the 12 step facilitation approach. Census sampling method was used for the addiction counsellors with the entire population participating in the study. A sample size of 134 respondents calculated using Yamane simplified formula was used for the recovering alcoholics. Data was collected using a structured questionnaire for the recovering alcoholics and addiction counsellors. The instruments were validated and adjustments done after the pilot study, while reliability was determined using the Cronbach's Alpha Coefficient at 0.898. The data was analysed using the IBM Statistical Package for Social Sciences (SPSS) version 22.0. Pearson correlations were used to test the relationship between the dependent variable (recovering alcoholics competencies) and the independent variable (AA 12 steps facilitation). The 12 steps facilitation was established to be statistically significant at $\mathrm{p}=0.000<0.05$ with a moderate positive association $(\mathrm{r}=0.491)$. The study recommends strengthening of key indicators under the AA 12 steps facilitation model established to positively contribute towards the development of competencies. These comprised of the aspects of self-acceptance of the person as an alcoholic, acknowledgement and the commitment of the alcoholic to continue seeking help that would promote high levels of rehabilitation success among alcoholics.
\end{abstract}

Keywords: Alcoholics Anonymous, 12 Steps Facilitation, Recovering Alcoholics, Competencies, Rehabilitation DOI: $10.7176 /$ RHSS/9-10-07

Publication date:May $31^{\text {st }} 2019$

\section{Introduction}

Alcohol intake is a phenomenon experienced among people of both gender and across different social economic backgrounds. The reasons for alcohol uptake range from recreational purposes after hard work, socialization purposes, celebration moments and during cultural events such as dowry negotiations. According to Musyoka (2013), alcohol is a colourless volatile flammable liquid, synthesized or obtained from fermentation of sugars and starches and widely used, either pure or denatured, as a solvent in drugs, cleaning solution, explosives and intoxicating beverages. Alcohol uptake has diverse effects on the human body depending on the dosage and length of time elapsed during the drinking period (Christensen, 2014). The psychological effects include feelings of guilt, shame, a poor sense of self-esteem, depression or loneliness, levels of decreased awareness and increased relaxation with the drinker becoming talkative or outgoing (Gallon \& Porter, 2012).

There are diverse alcoholism challenges and problems leading to the need for rehabilitation. Rehabilitation has been defined as the relearning or re-establishing healthy functioning, skills and values as well as regaining physical and emotional health (Musyoka, 2013). Kuria (2015) notes that rehabilitation is meant to provide full or partial restoration of physical, psychological or social functioning that has been damaged by a previous disease or condition through counselling. Alcoholism can be treated effectively if alcoholics can access treatment and rehabilitation services that are appropriate to their needs and of sufficient quality, intensity and duration (Hall, 2015). Recovery does not begin once an individual has completed treatment but forms an integral part of the treatment process which begins when an individual decides to address his or her substance use disorder. In Kenya, the first rehabilitation centre was started in 1986 at Asumbi, followed by Brightside DART center in 1998, Red Hill in 2001 and Mathare Addiction Center in 2003. By 2008, there were an estimated 61 registered rehabilitation centers in the country (Musyoka, 2013). Kuria (2015) further indicate that in the Kenyan context, 
the registered rehabilitation centers mostly admit patients for a 90 days programme without undergoing detoxification.

Within the context of the alcohol rehabilitation, the most widely used model is the 12 steps facilitation model popularized by the Alcoholics Anonymous (AA) group (Ingvarson \& Page, 2013). The AA group was formed in 1935 in Akron, Ohio, in the United States of America by two friends, Bill Wilson and Dr. Robert Smith, who assisted each other to overcome alcohol addiction. The two friends adopted and modified five steps that were being used by a Christian group called the Oxford Group for the people who were committing to Christianity through personal salvation (Mjwara, 2013). The Oxford Group used a five-stage process for indoctrinating new converts. These stages involved giving in to God, listening to God's direction, checking for guidance, achieving restitution and sharing. From these five stages, the AA expanded them to 12 steps while modifying them for use in alcoholics' rehabilitation (Marsh, Dale \& Willis, 2007). The twelve steps include admission of powerlessness over alcohol making life unmanageable, belief in a greater power to restore sanity, surrender to one's life and will to God, searching for a moral inventory over ones' life, admission of exact nature of wrong doings and leaving God to remove all defects of characters (Tonigan \& Connors, 2012). Other steps include the request to God to remove the alcoholic's shortcomings, making amends to wronged persons, continuance of making an inventory to correct wrong doings, use of prayers and mediations to improve the relationship with God and taking responsibilities to help other alcoholics (Brower et al., 2013). The 12 steps were later published in 1937 in what is referred to as the "big book".

The regaining of the psychological competencies lost during the alcoholic's life is critical in the rehabilitation process and may prevent lapsing back into alcoholism. The rehabilitation process therefore seeks to empower the alcoholic to embrace normal functioning human skills for the social, spiritual and economic life (McLeod, 2013). In this context, one of the most important human skills is the ability to use judgment and make choices and decisions both at personal and interpersonal levels, which in turn affects the quality of life. These competencies range from specific skills and abilities to general constructs such as self-esteem. Development of appropriate social and personal competencies among recovering alcoholics reflect their improved adjustment to deal with issues in the family, school, work and in society at large (Aissen, 2013).

\section{Objective of the study}

To determine the relationship between the Alcoholics Anonymous' 12 steps facilitation and development of recovering alcoholics' competencies in rehabilitation facilities in Central and Nairobi regions.

\section{Hypothesis of the study}

There is no statistically significant relationship between the Alcoholics Anonymous' 12 steps facilitation and development of recovering alcoholics' competencies in rehabilitation facilities in Central and Nairobi regions.

\section{Literature Review}

\section{Concept of Alcohol Addiction}

Alcohol addiction occurs when a person continues to use alcohol in the face of diverse effects on his or her health or life often despite repeated attempts to stop (Aissen, 2013). Addiction is not all physical but has a psychological dimension where individuals find themselves craving or hungering for alcohol and its effects even when they are not physically dependent (Brower, et al., 2013). This usually results from the powerfully rewarding effects that alcohol produces. Addiction is characterised by an inability to consistently abstain, impairment in behavioural control and craving, diminished recognition of significant problems with one's behaviours and interpersonal relationships and a dysfunctional emotional response (Gabhainn, 2003).

\section{The Alcoholics Anonymous 12 Steps Facilitation Model}

While there are diverse rehabilitation models for recovering alcoholics, the 12 steps facilitation model developed by the Alcoholics Anonymous organization is the most popular. However, different programmes that derive their steps from the original alcoholics anonymous 12 steps have emerged over the years with some attempting to address perceived weaknesses with the AA 12 steps facilitative model (Hall, 2015). The Willmar state hospital in the United States developed what came to be known as the Minnesota model (Githae, 2015). The goals of the Minnesota model include moving away from the simple custodial care of alcoholics, clarifying the distinction between detoxification and treatment and identifying a variety of elements of care within one programme (McCrady \& Longabaugh, 2012). The continuum of care components generally includes a diagnostic and referral center, a primary residential rehabilitation programme, an extended care programme, residential intermediate care such as the halfway houses, outpatient care, aftercare and a family programme (Witkiewitz \& Masyn, 2008).

The 12 alcohol recovery steps are attributed to the alcoholics anonymous groups which modified them from Oxford groups in 1935 (Morgenstern et al., 2014). The original AA 12 steps facilitative model was meant to last 
up to 60 days in a residential setting in the hope that a caring and low-stress environment removed from traditional daily life would facilitate the recovery process. This was however extended over the years to between 3 to 6 months ( Roozen, Blaauw. \& Meyers, 2009). Exploring the 12 steps during rehabilitation and sharing common experiences have been shown to create a sound support structure on which millions of current and former members of the AA have been able to rebuild their lives. The AA's 12 steps and traditions have been adapted by other addiction treatment groups that have altered words or principles out of the necessity to define their philosophy and goals appropriately. These salient traditions ensure that the rehabilitation facilities following the 12 steps can provide accessible, safe and therapeutic environments in which recovering alcoholics find acceptance, support, and fellowship, saving them from the devastations of alcohol addiction (Hollen, 2009).

The 12 -step facilitation approach offers alcoholics seeking recovery a new way of life that seeks to support their breaking the cycle of addiction and maintaining sobriety. The strengths and usefulness of the 12-step approach seem to have several sources. The 12 steps provide a developmental approach in addiction recovery. The steps are organized from the most basic changes onward to the more advanced changes that individuals motivated to recover may seek to incorporate into their life (Mercer \& Woody, 1999). The 12 steps model rehabilitation process success have been attributed to the programme's encouragement of the alcoholic's surrender to the rehabilitation process and recognises the need for treatment and development of personal spirituality practices as components for living in healthy recovery (Pagano, Post \& Johnson, 2010). This is because the ability of an alcoholic to accept their identity as an alcoholic and loss of control over their life marks the start of the recovery process. According to Aissen (2013), there are empirical results to suggest the centrality of the surrender benefits and the overall quality of the recovery of the alcoholics. The 12 steps facilitation models have been shown to score higher on surrender scales compared to alternative rehabilitation models (Bauer, 2015).

The 12-step rehabilitation process has also been associated with other skills and competencies critical for a recovering alcoholic (White \& Miller, 2007). The ability of the 12 step process for the members to maintain sobriety through sharing of experiences, strengths and hope with each other is critical for self-acceptance and improvement of self-esteem (Brower et al., 2013). This sharing of experiences and support structure ensures that the feeling of isolation and loneliness that recovering addicts feel is reduced hence aiding in the recovery process. Denzin (1987), indicates that there is a connection between how alcoholics learn to tell their story in AA and recovery, which helps persons recovering from alcohol addiction organise their past identification with the alcoholic self and realign it in terms of a recovering self. This sense of self is shaped through telling and retelling one's story during recovery. The 12 step process assists the recovering alcoholic to learn that alcoholism is a disease that denies them the ability to predict and control the alcohol consumption. The recovering addicts also become aware of destructive patterns of alcohol use, and come to acknowledge the loss of control over their drinking and learn to understand that recovery is a lifelong process (Cromin, 2013). The recovering addicts using the 12 steps model learn to admit wrong doing and make amends to those they have hurt and become responsible for the messages of recovery to others. The recovering alcoholics also learn how to overcome grief in the recovery process. The grief is occasioned by a feeling of loss over diverse aspects of the alcoholic's life such as career, family, health and financial concerns (Kuria, 2015). Alcoholics with such problems may successfully struggle through their personal conflicts with the help of psychiatrists and psychologists and benefit from the 12-step programme (Gwinnell \& Adamec, 2006).

Corey (2013), observes that the AA 12-step programme has worked very well for many alcoholics and indicates that once clients understand the nature of their chemical dependence and are no longer using drugs, their chances of making a recovery are greatly increased. This then makes it possible to focus on the other aspects of their lives that seem problematic (ibid). It is therefore possible to treat alcoholism and at the same time carry out a programme of individual therapy geared to changing the recovering alcoholics' ways of thinking, feeling and behaving. The AA 12 steps facilitation model was chosen because of its longstanding reputation as a viable treatment approach for alcoholism (Evans, 2010; Mosher-Ashley \& Rabon, 2001), as well as the fact that AA and its 12-step routine is the dominant method of treatment in most rehabilitation centers. The AA 12 steps facilitation approach comprised the independent variable that formed the rehabilitation factor for the study.

\section{Development of Social and Personal Competencies in Addiction Clients}

Competence is viewed as an integrative concept which refers broadly to the ability to develop adaptive responses to demands and capitalise on opportunities in the environment. The competent individual is one who is able to make use of environmental and personal resources to achieve a good developmental outcome. The possibilities range from specific skills and abilities to general constructs such as self-esteem. Social and personal competencies reflect adjustment of the alcoholic to deal with issues in the family, school and work and in the wider society. The focus on social competence is on particular aspects such as empathy, self-control, trust and respect for other people (Maside, 2011). In recent years, the study of social competencies has received increased attention from policy makers and social scientists across disciplines, partly due to increased concerns about the 
lack or erosion of social competencies in modern society (Odera, 2013).

Competencies are not considered innate but must be developed overtime in order to cultivate and improve performance and continue throughout a person's life (Roozen et al., 2009). Competency is also achieved through training and supervision from knowledgeable instructors and supervisors who in this study comprised of addiction counsellors (Kivlahan, 2013). Competency is achieved by the recovering alcoholic engaging in a journey of knowing and improving oneself. This involves seeking personal therapy, pursuing other healthy life activities and being honest about ones needs, shortcomings, fears and failures ( Brown, Emrick \& Glaser, 2012).

\section{Methodology}

Ex-post- facto correlational research design was adopted targeting an accessible population of 202 recovering alcoholics and 81 addiction counsellors in 17 rehabilitation facilities in Central and Nairobi regions employing the 12 step facilitation approach. Census sampling was used for addiction counsellors while Yamane simplified formula for the recovering alcoholics, yielding 134 respondents. Data was collected using structured questionnaires \& instruments validated \& adjustments done after the pilot study. Reliability was determined using Cronbach's Alpha coefficient that yielded 0.898. Pearson correlation tested the relationship between the independent and dependent variables.

\section{Findings and Discussions}

\section{Descriptive Statistics for AA 12 Steps Facilitation Model}

The indicators used for this examination included aspects of self-acceptance as an alcoholic, acknowledgement of the need for help, mending broken relationships, commitment to seeking help, coping with alcoholism challenges, regaining of control over personal responsibility, maintenance of sobriety through AA support system, the resolve to stay sober and creation of new social structures. For the descriptive statistics, this study employed the use of the mean and standard deviation to analyse the obtained data for the five study variables. The study used the mean to describe the sample with a single value that represents the centre of the data. The results are as displayed in Table 1.

Table 1: Frequency Distributions of the AA 12 Steps Facilitation Model

\begin{tabular}{|c|c|c|c|c|c|c|c|}
\hline \multirow[b]{2}{*}{ AA 12 Steps Indicators } & \multicolumn{7}{|c|}{ Percentages and Frequencies } \\
\hline & SA & A & $\mathrm{U}$ & $\mathrm{D}$ & SD & Mean & $\begin{array}{l}\text { Std } \\
\text { Dev }\end{array}$ \\
\hline Self-acceptance as an alcoholic & $\begin{array}{l}46.9 \% \\
82\end{array}$ & $\begin{array}{l}30.3 \% \\
53\end{array}$ & $\begin{array}{l}6.3 \% \\
11\end{array}$ & $\begin{array}{l}6.3 \% \\
11\end{array}$ & $\begin{array}{l}10.3 \% \\
18\end{array}$ & 3.97 & 1.111 \\
\hline Acknowledgement of the need for help to get better & $\begin{array}{l}44.0 \% \\
77\end{array}$ & $\begin{array}{l}36.0 \% \\
63\end{array}$ & $\begin{array}{l}9.1 \% \\
16\end{array}$ & $\begin{array}{l}3.4 \% \\
6\end{array}$ & $\begin{array}{l}7.4 \% \\
13\end{array}$ & 4.06 & 0.958 \\
\hline Taking stock of past and admit wrong doing & $\begin{array}{l}35.4 \% \\
62\end{array}$ & $\begin{array}{l}43.4 \% \\
76\end{array}$ & $\begin{array}{l}9.1 \% \\
16\end{array}$ & $\begin{array}{l}0.6 \% \\
1\end{array}$ & $\begin{array}{l}11.4 \% \\
20\end{array}$ & 3.91 & 1.024 \\
\hline Mend broken relationships & $\begin{array}{l}29.7 \% \\
52\end{array}$ & $\begin{array}{l}36.0 \% \\
63\end{array}$ & $\begin{array}{l}18.3 \% \\
32\end{array}$ & $\begin{array}{l}7.4 \% \\
13\end{array}$ & $\begin{array}{l}8.6 \% \\
15\end{array}$ & 3.71 & 1.013 \\
\hline Commit to continuing to seek help to get better & $\begin{array}{l}42.9 \% \\
75\end{array}$ & $\begin{array}{l}36.0 \% \\
63\end{array}$ & $\begin{array}{l}8.6 \% \\
15\end{array}$ & $\begin{array}{l}5.1 \% \\
9\end{array}$ & $\begin{array}{l}7.4 \% \\
13\end{array}$ & 4.02 & 0.982 \\
\hline $\begin{array}{l}\text { Regain control over personal responsibility over } \\
\text { daily living dynamics e.g. diet, hygiene, sleep }\end{array}$ & $\begin{array}{l}35.4 \% \\
62\end{array}$ & $\begin{array}{l}38.9 \% \\
68\end{array}$ & $\begin{array}{l}11.4 \% \\
20\end{array}$ & $\begin{array}{l}5.1 \% \\
9\end{array}$ & $\begin{array}{l}9.1 \% \\
16\end{array}$ & 3.86 & 1.019 \\
\hline $\begin{array}{l}\text { Maintain sobriety through support system in the } \\
\text { AA community }\end{array}$ & $\begin{array}{l}37.7 \% \\
66\end{array}$ & $\begin{array}{l}39.4 \% \\
69\end{array}$ & $\begin{array}{l}8.6 \% \\
15\end{array}$ & $\begin{array}{l}8.0 \% \\
14\end{array}$ & $\begin{array}{l}6.3 \% \\
11\end{array}$ & 3.94 & 0.963 \\
\hline $\begin{array}{l}\text { Strengthen resolve to stay sober through helping } \\
\text { others stay sober }\end{array}$ & $\begin{array}{l}30.9 \% \\
54\end{array}$ & $\begin{array}{l}44.6 \% \\
78\end{array}$ & $\begin{array}{l}10.3 \% \\
18\end{array}$ & $\begin{array}{l}4.0 \% \\
7\end{array}$ & $\begin{array}{l}10.3 \% \\
18\end{array}$ & 3.82 & 1.013 \\
\hline $\begin{array}{l}\text { Create new social structure and friends that help } \\
\text { recovery }\end{array}$ & $\begin{array}{l}34.9 \% \\
61\end{array}$ & $\begin{array}{l}39.4 \% \\
69\end{array}$ & $\begin{array}{l}12.0 \% \\
21\end{array}$ & $\begin{array}{l}5.7 \% \\
10\end{array}$ & $\begin{array}{l}8.0 \% \\
14\end{array}$ & 3.87 & 0.987 \\
\hline
\end{tabular}

The results displayed in Table 1 indicate that self-acceptance as an aspect of AA 12 steps facilitation model achieved a mean of 3.97 and a standard deviation of 1.111. The mean of 3.97 implies that the respondents on average tended to agree that the concept of self-acceptance as an alcoholic was achieved during their stay in rehabilitation. This was due to means lying between 3.5 and 4.5 in a five point likert scale as indicated by (Moffatt, 2015). This is further evidenced by a cumulative percentage of $77.2 \%$ of the respondents who chose the strongly agree and agree metrics respectively. The high standard deviation of 1.111 indicated a huge spread of data from the mean of 3.97. This can be attributed to significant scores of respondents who disagreed and strongly disagreed with the metric at $6.3 \%$ and $10.3 \%$ respectively. The results achieved in respect to this indicator were consistent with those of Brower et al.(2013), that point out on the ability of the 12 step process in helping members maintain sobriety through sharing of experiences, strengths and hope with each as well as promoting self-acceptance and improvement of a person's self-esteem. This component of the 12 step process 
assists the recovering alcoholic to learn that alcoholism is a disease that denies one of the ability to predict and control alcohol consumption (Cromin, 2013). The recovering addict also become aware of destructive patterns of alcohol use and helps to come to terms with their loss of control over drinking and learn to understand that recovery is a lifelong process (ibid).

The indicator that the AA 12 steps led to the acknowledgement for the need to get help in getting better had means and standard deviation scores of 4.06 and 0.958 respectively. This mean of 4.06 implied that the respondents on average tended to agree that AA 12 steps led to respondents acknowledging their need for help to move towards sobriety. This can further be evidenced by a relatively high score of $80.0 \%$ in respect to the respondents who agreed and strongly agreed as opposed to $9.1 \%, 3.4 \%$, and $7.4 \%$ of the respondents who were uncertain, disagreed and strongly disagreed respectively. A standard deviation of 0.958 indicated a moderate score spread from the mean hence implying moderate consensus amongst the respondents in respect to the achieved average mean. Proponents of the person-centered theory indicate that each individual has within him or her capacity for dramatic and positive growth (Cloete, 2014). The study results agree with findings by Coombs \& Howatt, (2005), that indicate that termination of all alcohol addiction occurs when persons facing addiction recognise that mood-altering substances do not offer support as they had initially thought, but form the basis of increasing their problems. The findings are consistent with Gwinnell \& Adamec (2006), who observe that a recovering alcoholic's acceptance of the presence of an addiction problem becomes the foundation of their path to recovery. This awareness alone however is not sufficient, but forms a necessary element of overcoming their addiction (ibid).

The ability of the respondents to take stock of the past and admit wrong doing was noted as a key component influencing development of recovering alcoholic competencies in rehabilitation centres. In this context, the indicator scored a mean of 3.91 and a standard deviation of 1.024. The mean score of 3.91 in a five point likert scale indicated that the respondents on average agreed that this AA step enabled them take stock of the past and admit to wrong doing. However, there were a notable number of respondents who were uncertain, disagreed and strongly disagreed. The prevalence of these thoughts stood at $9.1 \%, 0.6 \%$, and $11.4 \%$ scores for uncertain, disagree and strongly disagree responses respectively. These findings are consistent with those by Denzin (1987), which established the presence of a relationship between how alcoholics learn to tell their story in AA and recovery, which helps recovering alcoholics organise their past identification with the alcoholic self and redefine it in terms of a new recovering self. This sense of self is shaped by the telling and retelling of one's encounters during recovery. The recovering addict also become aware of destructive patterns of alcohol use and come to acknowledge the loss of control over their drinking and learn to understand that recovery is a lifelong process (Cromin, 2013). The recovering alcoholic therefore learns to use this indicator of taking stock of the past and admitting wrong doing to make amends to those they have hurt and becoming responsible for the messages of recovery to others (Kuria, 2015). The study findings resonate with the views of Adlerian theorists that places keen interest in the future of recovering alcoholics without minimising the importance of past influences. These views assume that decisions are based on the person's experiences on the present situation and in the direction that the person is moving towards (Mcveigh, 2012).

This study also established that the respondents agreed that rehabilitation helped them to mend broken relationships as indicated by achieved scores of 3.71 and 1.013 for the means and standard deviations respectively. The high mean score of 3.71 in a five point likert scale indicates that the respondents on average tended to agree that this aspect of the AA step helped in mending of broken relationships. This can further be evidenced by respondents who indicated strongly agree and agree at $29.7 \%$ and $36.0 \%$ respectively in respect to the metric. However, significant percentages of $7.4 \%$ and $8.6 \%$ of the respondents who disagreed and strongly disagreed with the metric led to a large standard deviation of 1.013 that implied lack of consensus in respect to the achieved mean score amongst the respondents. Alcoholics Anonymous has been viewed as a strong avenue in its approach to helping participants recover from alcohol dependency (Hollen, 2009). Rehabilitation from alcohol is critical due to the fact that alcoholism often destroys critical family relationships due to violence, marital satisfaction inadequacies, economic challenges and general family happiness (Peter, 2015). The results are consistent with findings by Saatcioglu, Erim \& Cakmak (2006), that provide strong evidence supporting the effectiveness of family interventions in the treatment of alcoholism, demonstrating that family therapy for alcoholics is effective in improving overall family relationships and functioning. This has been shown to improve overall substance use outcomes, engagement and retention in therapy for recovering alcoholics (ibid). Critics of the 12 steps however lay claim that the AA is cult-like and tends to foster dependent relationships in which long-term members exploit newer and vulnerable members seeking treatment (Hollen 2009).

A mean score of 4.02 and a standard deviation score of 0.982 was achieved in respect to the AA 12 Step indicator that sought to assist the rehabilitation respondents to continue seeking help to get better. A mean score of 4.02 in a five point likert scale indicated that the respondents on average tended to agree that this AA 12 step helped respondents to continuously seek for help to get better during the rehabilitation period. The standard deviation of 0.982 implied a moderate consensus in respect to the achieved mean score. The findings are 
consistent Moos (2010), who observes that individuals actively involved in meetings and other group-related activities are more likely to socialise with close friends, be involved in sports, attend cultural events and engage in community activities with a higher likelihood of achieving and maintaining abstinence.

The results of table 1 revealed that the AA 12 step led to regaining of control over personal responsibility over daily living dynamics like diet, hygiene and sleep among others and achieved a mean of 3.86 and standard deviation of 1.019 . Most of the $(38.9 \%)$ respondents were inclined to agreeing that the AA step indeed helps recovering alcoholics regain control over personal responsibility over daily living dynamics such as diet, hygiene and sleep, closely followed by those who were inclined to strongly agree (35.4\%) on the same. These findings agree with Fidelis (2012), who argues that the restoration of daily life for the recovering alcoholic is centred on traditions that focus on the restoration of the regular day to day activities. The results resonate with findings by Mjwara (2013), who points out that acts of personal responsibility require the recovering alcoholic to create new habits that deal with his daily lifestyle such as his diet, hygiene, sleep, exercise, clothes and recreational activities which are core components in rehabilitation.

The maintenance of sobriety through support systems in the AA community scored a mean of 3.94 and standard deviation of 0.963 . The relatively high mean implied a tendency for the respondents to agree on average in respect to the metric and a moderate standard deviation implied a moderate consensus on the mean. This is further illustrated by the frequencies. The AA step helps recovering alcoholics maintain sobriety through a support system in the AA community (Strongly Agree $=37.7 \%$; Agree $=39.4 \%$ ). However, there were $8.0 \%$ and $6.3 \%$ of respondents who disagreed and strongly disagreed that this AA Model helps recovering alcoholics to maintain sobriety through support system in the AA community, respectively. The findings reported in respect to this indicator are consistent with those of Hollen (2009), that indicate exploration of the 12 steps during rehabilitation and sharing of common experiences among recovering alcoholics have been shown to create a solid support structure on which millions of former and current members have been able to rebuild their lives. The rehabilitation facilities embracing the main traditions of the 12 steps were noted to provide accessible, safe and therapeutic environments in which recovering alcoholics find acceptance, support and fellowship, saving them from the ravages of alcohol addiction (ibid). The 12 -step facilitation approach offers clients seeking recovery a new way of living that seeks to support their breaking the cycle of addiction and maintaining sobriety. The findings further agree with Brower et al. (2013), which observe that the sharing of experiences and support structures ensure that the feeling of isolation and loneliness that the recovering addicts feel are significantly reduced aiding in the recovery process.

Results presented in table 1 revealed that strengthening of the resolve to stay sober through the helping of others stay sober had achieved means and standard deviation scores of 3.82 and 1.013 respectively. This can further be illustrated by the frequency distribution of $30.9 \%$ and $44.6 \%$ of the respondents who indicated responses of strongly agree and agree respectively. This implied that the respondents on average agreed that the AA step helped in strengthening their resolve to stay sober. The findings in respect to this indicator are consistent with Zemore \& Kaskutas (2008), which point to the fact that individuals involved in helping others during treatment by volunteering, providing moral support and encouragement as well as sharing their knowledge about how to remain sober, tended to achieve improvements in the short term during recovery. The findings concur with studies by Pagano et al. (2004), that indicated recovering individuals keen on helping their peers maintain long-term sobriety after treatment were themselves better able to maintain sobriety, probably as a result of the social rewards that came from providing support for others. The study findings are consistent with Crape et al. (2002) that point out to the essence of engagement in helping activities by recovering alcoholics which improves their self-esteem and social standing. The resolve to seek sobriety strengthens their social network and provides a model of successful commitment to living a sober lifestyle following their discharge from the rehabilitation facility (ibid). This acceptance that the recovering alcoholic has an addictive problem becomes the cornerstone for their path to recovery and forms a necessary element of overcoming the addiction (Gwinnell \& Adamec, 2006).

In respect to the AA rehabilitation process helping in creation of new social structure and friendship that can help in recovery, mean and standard deviation scores of 3.87 and 0.987 respectively were achieved. This can further be illustrated through scores of $34.9 \%$ and $39.4 \%$ of the respondents who strongly agreed and agreed respectively. The respondents on average tended to agree that the rehabilitation process helped in creation of new social structures and friendship. These results resonate with findings by Musyoka (2013), that observe that once a recovering alcoholic becomes aware of the maladaptive patterns present in their life, they get in a position to modify the faulty assumptions and make basic changes and create a new style of life. These results agree with the Association for Addiction Professionals (2009), that point out the need for appropriate use of Adlerian psychology in identifying and correcting misguided beliefs that directly influence how a person becomes an addict. As a therapeutic approach, Adlerian psychology is powerful in empowering recovering alcoholics develop a positive, sober lifestyle, a sense of belonging and learning how to change current behaviours to those that are more useful and productive (ibid). 
Relationship between AA 12 steps facilitation and development of recovering alcoholics' competencies.

The relationship between Alcoholics Anonymous' 12 steps facilitation and recovering alcoholics competencies was determined using Pearsons correlation coefficient. All tests were done at coefficient alpha $(\alpha)$ equal to 0.05 . Wilson and MacLean (2011) confirm that Pearson's correlation coefficient is suitable when both variables that the researcher wishes to study are measured in either interval or ratio scales and are continuous. Table 2 summarizes the results.

Table 2: Relationship between AA 12 steps facilitation and development of recovering alcoholics competencies

\begin{tabular}{lll}
\hline & & Recovering Alcoholics Competencies \\
AA 12 Steps & Pearson Correlation & 0.491 \\
& Sig. (1 tailed) & 0.000 \\
\hline
\end{tabular}

$\mathrm{r}=.491$, Significance at .05

As indicated in table 2, the Pearson's correlation coefficient yielded an $\mathrm{r}$ value of .491 and a $\mathrm{P}$ value of .000 . On the basis of $p<.05$, the null hypothesis that stated that there was no statistically significant relationship between the Alcoholic Anonymous' 12 steps facilitation and development of recovering alcoholics' competencies in rehabilitation facilities was rejected. This implied that a statistically significant relationship exists between Alcoholic Anonymous' 12 steps facilitation and recovering alcoholic competencies. Table 2 confirms that development of competencies among recovering alcoholics is positively and moderately associated with the AA 12 steps facilitation at a confidence level of $95 \%(p=0.000<.05)$. The moderate positive association between development of competencies and AA 12 steps facilitation indicated that when the AA 12 steps facilitation increases, development of competencies among recovering alcoholics is likely to increase.

These findings are consistent with Mercer\& Woody (1999), that indicate that the 12 -step facilitation approach offers clients seeking recovery a new way of life that seeks to support their breaking the cycle of addiction and maintaining sobriety. The 12 steps are organized from the most basic changes onward to the more advanced changes that individuals motivated to recover may seek to incorporate into their lifestyle. The study findings also agree with White \& Miller (2007), who content that the 12-step rehabilitation process has been associated with development of skills and competencies viewed as critical for a recovering alcoholic. The findings are consistent with studies by Brower et al. (2013), which observe that the ability of the 12 step process in contributing to alcoholics in maintaining sobriety through sharing of experiences, strengths and hope with each other is critical for self-acceptance and improvement of their self-esteem.

Previous studies done on development of competencies suggest that competencies can be achieved by the recovering alcoholic engaging in a journey of knowing and improving oneself that involves seeking personal therapy, pursuing other healthy life activities and being honest about ones needs, shortcomings, fears and failures (Brown et al., 2012). This hypothesis has therefore been supported by findings that show that rehabilitation programmes modelled along the 12-step principles such as the AA programmes have registered high levels of rehabilitation success among alcoholics (Aissen, 2013). This view is supported by findings by Brower et al. (2013), that indicate the sharing of experiences and support structures ensures that feelings of isolation and loneliness experienced by the recovering alcoholic are reduced hence aiding in the recovery process. This view is further supported by Corey (2013), who observes that the AA 12-step programme has worked well for many alcoholics who on understanding the nature of their chemical dependence are able to abstain from alcohol, increasing their chances of making a recovery. This focus of Behavioural therapy is on increasing the skills of recovering alcoholics and providing them with more options for responding to situations (Corey, 2013). The recovering alcoholic gets an opportunity to learn new and adaptive behaviours by being engaged in the AA 12 steps that eventually lead to replacement of old and maladaptive behaviours. The AA 12 steps approach further gets support from the person-centered therapy, through the mechanisms that provide recovering alcoholics with forums to talk about their past, present or future (Kraemer, 2012).

\section{Conclusion}

The study concluded that AA 12 steps facilitation model has a moderate influence in promoting development of competencies among recovering alcoholics. Key indicators under the AA 12 steps that would require more focus during the recovery process include the aspects of self-acceptance of the person as an alcoholic, acknowledgement and the commitment of the alcoholic to continue seeking help that would promote high levels of rehabilitation success among alcoholics.

\section{Recommendation}

The study recommends strengthening of key indicators under the AA 12 Steps Facilitation Model that were established to positively contribute towards the development of competencies among recovering alcoholics. Theses indictors included aspects of self-acceptance of the person as an alcoholic, acknowledgement and the commitment of the alcoholic in continuing to seek help. 


\section{References}

Aissen, K. A. (2013). Personal Factors Influencing Impaired Professionals' Recovery from Addiction. International Journal of Humanities and Social Sciences, 2(4), 45-54.

Association for Addiction Professionals (2009). The Basics of Addiction Counseling: Desk Reference and Study Guide Module II: Addiction Counseling Theories, Practices and Skills. NAADAC, Alexandria, VA.

Bauer, M. (2015). Alcoholism and Drug Addiction; The Useless Side of Life. IOSR Journal of Humanities and Social Science, 1(2), 45-49.

Brower, K. J., Aldrich, M. S., Robinson, E. A. R., Zucker, R. A., \& Greden, J. F. (2013). Insomnia, selfmedication, and Relapse to Alcoholism. American Journal of Psychiatry, 158(3), 399-404.

Brown, S., Emrick, C., \& Glaser, F. (2012). Research on Alcoholics Anonymous: Opportunities and Alternative Conferences. Journal for Family and Community Ministries, 2(4), 98-110.

Christensen, P. A. (2014). Alcoholism and Masculinity in Japan. Journal of Studies of Alcohol and Drugs, 2(3), 49-54.

Cloete, N. (2014). Spouses' Experience of a Shared Alcohol Rehabilitation Involvement: An Interpretative Phenomenological Analysis. International Journal of Advanced Research, 2(3), 49-52.

Coombs R.H. \& Howatt W.A. (2005).The Addiction Counselor's Desk Reference. John Wiley \& Sons, Inc. New Jersey.

Corey, G. (2013)Theory and Practice of Counseling and Psychotherapy. Brooks \& Cole California

Crape, B.L., Latkin C.A., Laris, A.S. \& Knowlton, A.R. (2002). The Effects of Sponsorship in 12-step Treatment of Injection Drug Users. Drug, Alcohol \& Dependency. 65:291-301.

Cromin, J. (2013). Impulsivity and Self Esteem as Predictors of Alcohol Use among Irish Adults. IOSR Journal Of Humanities And Social Science Ver. I, 4(9), 1689-1699.

Denzin, N. (1987). The Recovering Alcoholic (Sociological observation; 19). Newbury Park: Sage Publications.

Evans, T. E. (2010). Sober and Alone: A Phenomenological Exploration of the Loneliness Experienced by Recovering Alcoholics. Doctorate Dissertation in Counselling. Liberty University, Lynchburg, Virginia.

Fidelis, M. (2014). The Effects of Harmful Alcohol Use on the Quality of Marital Relationships: A Study of Patients at Rehabilitation Centres in Nairobi. Journal for Family and Community Ministries, 2(3), 58-64.

Gabhainn, S. N. (2003). Assessing Sobriety and Successful Membership of Alcoholics Anonymous. Journal of Substance Use, 8(1), 55-61.

Gallon, S., \& Porter, J. (2012). Performance Assessment Rubrics for the Addiction Counseling Competencies. Journal of Humanities, 1(3), 95-100.

Githae, N. (2015). Relationship Between Family Expressed Emotion and Relapse Occurrence among Inpatient Alcoholics in Nairobi County, Kenya. Journal for Family and Community Ministries, 2(3), 74-84.

Gwinnell, E. \& Adamec C. (2006).The Encyclopedia of Addictions and Addictive Behaviours. FactsOn File, Inc. New York.

Hall, T. (2015). Rethinking Drinking: A Paradigm Shift for Estimating Social and Behavioural Harm. IOSR Journal Of Humanities And Social Science Ver. I, 2(3), 89-94.

Hollen K. H. (2009). Encyclopedia of Addictions, Greenwood Press, Connecticut.

Ingvarson, C., \& Page, R. (2013). Alcoholics Anonymous and the Counseling Profession: Philosophies in Conflict. Journal of Counseling and Development :, 2(6), 603-615.

Kivlahan, D. (2013). Alcoholism, Alcohol Abuse and Health in American Indians and Alaska Natives. The American Journal of Drug and Alcohol Abuse, 2(3), 54-62.

Kraemer, J. L. (2012). A Correlational Study of Self-Esteem and Family Support in Adult Children of Alcoholics and Adult Children of Non-Alcoholic. Journal of Alcohol \& Drug Education, 2(3), 96-105.

Kuria, M. (2015). Cost Effectiveness of Community Based and Institution Based Detoxification and Rehabilitation of Alcohol Dependent Persons in Kenya. IOSR Journal of Humanities and Social Science, 2(3), 104-109.

Marsh, A., Dale, A., \& Willis, L. (2007). An Examination into Counsellor's Role in Rehabilitation of Alcohol and Drug Users. IOSR Journal of Humanities and Social Science, 1(2), 105-110.

Maside, W. (2011). Effects of Illicit Brew Drinking and Intervention Measures on Unemployed Youth in Bungoma County, Kenya. Journal for Family and Community Ministries, 2(3), 54-60.

McCrady, B., \& Longabaugh, R. (2012). Cost Effectiveness of Alcoholism Treatment in Partial Hospital Versus Inpatient Settings after Brief Inpatient Treatment: 12-Month Outcomes. Journal of Consulting and Clinical Psychology, 54(5), 708-713.

McLeod, J. (2013). Alcoholic Women in Recovery; A Phenomenological Inquiry of Spirituality and Recidivism Prevention. Journal of Addictive Diseases, 2(9), 742-749.

Mcveigh, A. K. (2012). Spirituality in Practice; An Exploration into Narrative Practitioners' Approaches to Addressing Spirituality in Counselling Practices. Journal of Alcohol \& Drug Education, 2(1), 110-115. 
Mercer,D. E. \& Woody,G.E. (1999). Individual Drug Counseling : Therapy Manuals for Drug Addiction Series. U.S. Department of Health and Human Services, Rockville, Maryland

Mjwara, H. (2013). Exploring the Parent Child Relationship in Youth Abusing Alcohol. IOSR Journal of Humanities and Social Science, 2(3), 154-160.

Moos, R.H. (2010). Processes that Promote Recovery from Addictive Disorders. Kelly J.F. \& White W.L (eds.), Current Clinical Psychiatry, Addiction Recovery Management, Theory, Research and Practice, DOI: 10.1007/978-1-60327-960-4_4, Springer Science Business Media,

Mosher-Ashley, P. \& Rabon, C. (2001). A Comparison of Older and Younger Adults Attending Alcoholics Anonymous. Clinical Gerontologist, 24(1/2), 27-37.

Morgenstern, J., Labouvie, E., Mccrady, B. S., Kahler, C. W., Frey, R. M., \& Prey, R. M. (2014). Affiliation with Alcoholics Anonymous after treatment: A Study of its Therapeutic Effects and Mechanisms of Action. Journal of Consulting and Clinical Psychology, 65(5), 768-777.

Musyoka, C. M. (2013). A Situation Analysis of the Treatment Models Used in Registered Inpatient Alcohols and Drug Rehabilitation Centers in and Around Nairobi. IOSR Journal of Nursing and Health Science (IOSR-JNHS), 1(3), 74-84.

Odera, T. (2013). Effectiveness of Rehabilitation Programmes on Juvenile Delinquents in Kenya. Journal Nordic Studies on Alcohol and Drugs, 2(3), 89-99.

Pagano, M. E., Post, S. G., \& Johnson, S. M. (2010). Alcoholics Anonymous-Related Helping and the Helper Therapy Principle. Alcoholism Treatment Quarterly, 2(3), 23-34.

Peter, R. (2015). Attachment, Locus of Control and Romantic Intimacy in Adult Children of Alcoholics; A Correlational Investigation. International Journal of High Risk Behaviours and Addiction, 1(2), 87-93.

Roozen, H. G., Blaauw, E. \& Meyers, R. J. (2009). Advances in Management of Alcohol Use Disorders and Intimate Partner Violence: Community Reinforcement and Family Training. Psychiatry, Psychology and Law, 16(sup1), S74-S80. https://doi.org/10.1080/13218710802549456.

Saatcioglu, O., Erim, R., \& Cakmak, D. (2006). Role of Family in Alcohol and Substance Abuse. Review Article, Psychiatry and Neurosciences, 60(2), 125-132.

Tonigan, J. S. \& Connors, G. J. (2012). Special Populations in Alcoholics Anonymous. IOSR Journal of Humanities and Social Science, 2(4), 281-285.

White, W. L., \& Miller, W. R. (2007). The Use of Confrontation in Addiction Treatment: History, Science and Time for Change. Counselor, 8(4), 12-30.

Wilson, S. \& Maclen, R. (2011). Research Methods and Data Analysis for Psychology. McGraw Hill, Berkshire. Witkiewitz, K., \& Masyn, K. E. (2008). Drinking Trajectories Following an Initial Lapse. Psychology of Addictive Behaviors, 22(2), 157-167. https://doi.org/10.1037/0893-164X.22.2.157

Zemore, S.E. \& Kaskutas, L.A. (2008). Twelve-step Involvement and Peer Helping in Day Hospital and Residential Programs. Substance Use \& Misuse. 43:1882-903. 